\title{
Uses and Gratifications Theory in the 21st Century
}

\author{
Thomas E. Ruggiero \\ Communications Department \\ University of Texas at El Paso
}

\begin{abstract}
Some mass communications scholars have contended that uses and gratifications is not a rigorous social science theory. In this article, I argue just the opposite, and any attempt to speculate on the future direction of mass communication theory must seriously include the uses and gratifications approach. In this article, I assert that the emergence of computer-mediated communication has revived the significance of uses and gratifications. In fact, uses and gratifications has always provided a cutting-edge theoretical approach in the initial stages of each new mass communications medium: newspapers, radio and television, and now the Internet. Although scientists are likely to continue using traditional tools and typologies to answer questions about media use, we must also be prepared to expand our current theoretical models of uses and gratifications. Contemporary and future models must include concepts such as interactivity, demassification, hypertextuality, and asynchroneity. Researchers must also be willing to explore interpersonal and qualitative aspects of mediated communication in a more holistic methodology.
\end{abstract}

What mass communication scholars today refer to as the uses and gratifications ( $\mathrm{U} \& \mathrm{G})$ approach is generally recognized to be a subtradition of media effects research (McQuail, 1994). Early in the history of communications research, an approach was developed to study the gratifications that attract and hold audiences to the kinds of media and the types of content that satisfy their social and psychological needs (Cantril, 1942). Much early effects research adopted the experimental or quasi-experimental approach, in which communication conditions were manipulated in search of general lessons about how better to communicate, or about the unintended consequences of messages (Klapper, 1960).

Requests for reprints should be sent to Tom Ruggiero, Print Journalism, 102-B Cotton Memorial Communication Department, University of Texas, El Paso, TX 79968. E-mail: truggier@miners. utep.edu 
Other media effects research sought to discover motives and selection patterns of audiences for the new mass media. Examples include Cantril and Allport (1935) on the radio audience; Waples, Berelson, and Bradshaw (1940) on reading; Herzog $(1940,1944)$ on quiz programs and the gratifications from radio daytime serials; Suchman (1942) on the motives for listening to serious music; Wolfe and Fiske (1949) on children's interest in comics; Berelson (1949) on the functions of newspaper reading; and Lazarsfeld and Stanton $(1942,1944,1949)$ on different media genres. Each of these studies formulated a list of functions served either by some specific content or by the medium itself:

To match one's wits against others, to get information and advice for daily living, to provide a framework for one's day, to prepare oneself culturally for the demands of upward mobility, or to be reassured about the dignity and usefulness of one's role.

(Katz, Blumler, \& Gurevitch, 1974, p. 20)

This latter focus of research, conducted in a social-psychological mode, and audience based, crystallized into the U\&G approach (McQuail, 1994).

Some mass communication scholars cited "moral panic" and the Payne Fund Studies as the progenitor of U\&G theory. Undertaken by the U.S. Motion Picture Research Council, the Payne Fund Studies were carried out in the late 1920s. Leading sociologists and psychologists including Herbert Blumer, Philip Hauser, and L. L. Thurstone sought to understand how movie viewing was affecting the youth of America (Lowery \& DeFleur, 1983). Rosengren, Johnsson-Smaragdi, and Sonesson (1994), however, argued that the Payne Fund Studies were primarily effects-oriented propaganda studies, as opposed to the U\&G tradition, which focuses on research of individual use of the media. Likewise, Cantril's (1940) study of Orson Welles's "War of the Worlds" radio broadcast was more narrowly interested in sociological and psychological factors associated with panic behavior than in developing a theory about the effects of mass communication (Lowery \& DeFleur, 1983).

Wimmer and Dominick (1994) proposed that U\&G began in the 1940s when researchers became interested in why audiences engaged in various forms of media behavior, such as listening to the radio or reading the newspaper. Still others credit the U\&G perspective with Schramm's (1949) immediate reward and delayed reward model of media gratifications (Dozier \& Rice, 1984).

Regardless, early U\&G studies were primarily descriptive, seeking to classify the responses of audience members into meaningful categories (Berelson, Lazarsfeld, \& McPhee, 1954; Katz \& Lazarsfeld, 1955; Lazarsfeld, Berelson, \& Gaudet, 1948; Merton, 1949).

Most scholars agree that early research had little theoretical coherence and was primarily behaviorist and individualist in its methodological tendencies (McQuail, 1994). The researchers shared a qualitative approach by attempting to group gratifi- 
cation statements into labeled categories, largely ignoring their frequency distribution in the population. The earliest researchers for the most part did not attempt to explore the links between the gratifications detected and the psychological or sociological origins of the needs satisfied. They often failed to search for the interrelations among the various media functions, either quantitatively or conceptually, in a manner that might have led to the detection of the latent structure of media gratifications.

Criticisms of early $U \& G$ research focus on the fact that it (a) relied heavily on self-reports, (b) was unsophisticated about the social origin of the needs that audiences bring to the media, (c) was too uncritical of the possible dysfunction both for self and society of certain kinds of audience satisfaction, and (d) was too captivated by the inventive diversity of audiences used to pay attention to the constraints of the text (Katz, 1987). Despite severe limitations, early researchers, especially those at the Bureau of Applied Social Research of Columbia University, persevered, particularly in examining the effects of the mass media on political behavior. They studied voters in Erie County, Ohio, during the 1940 election between Roosevelt and Wilkie (Lazarsfeld et al., 1948) and voters in Elmira, New York, during the 1948 Truman-Dewey election (Berelson et al., 1954). Both studies suggested that the mass media played a weak role in election decisions compared with personal influence and influence of other people. As a result, Berelson et al. began amplifying the two-step flow theory, moving away from the concept of an "atomized" audience and toward the impact of personal influence (Katz, 1960).

\section{S AND 1960S RESEARCH}

Despite disagreement by communication scholars as to the precise roots of the approach, in the next phase of U\&G research, during the 1950s and 1960s, researchers identified and operationalized many social and psychological variables that were presumed to be the precursors of different patterns of consumption of gratifications (Wimmer \& Dominick, 1994). Accordingly, Schramm, Lyle, and Parker (1961) concluded that children's use of television was influenced by individual mental ability and relationships with parents and peers. Katz and Foulkes (1962) conceptualized mass media use as escape. Klapper (1963) stressed the importance of analyzing the consequences of use rather than simply labeling the use as earlier researchers had done. Mendelsohn (1964) identified several generalized functions of radio listening: companionship, bracketing the day, changing mood, counteracting loneliness or boredom, providing useful news and information, allowing vicarious participation in events, and aiding social interaction. Gerson (1966) introduced the variable of race and suggested that race was important in predicting how adolescents used the media. Greenberg and Dominick (1969) concluded that race and social class predicted how teenagers used television as an informal source of learning. 
These studies and others conducted during this period reflected a shift from the traditional effects model of mass media research to a more functionalist perspective. Klapper (1963) called for a more functional analysis of U\&G studies that would restore the audience member to "his rightful place in the dynamic, rather than leaving him in the passive, almost inert, role to which many older studies relegated him" (p. 527). Markedly, Geiger and Newhagen (1993) credited Klapper with ushering in the "cognitive revolution" in the communication field. From the 1950s forward, cross-disciplinary work between U\&G researchers and psychologists has produced abundant research on the ways human beings interact with the media.

\section{S RESEARCH}

Until the 1970s, U\&G research concentrated on gratifications sought, excluding outcomes, or gratifications obtained (Rayburn, 1996). During the 1970s, U\&G researchers intently examined audience motivations and developed additional typologies of the uses people made of the media to gratify social and psychological needs. This may partially have been in response to a strong tide of criticism from other mass communication scholars. Critics such as Elliott (1974), Swanson (1977), and Lometti, Reeves, and Bybee (1977) stressed that U\&G continued to be challenged by four serious conceptual problems: (a) a vague conceptual framework, (b) a lack of precision in major concepts, (c) a confused explanatory apparatus, and (d) a failure to consider audiences' perceptions of media content.

U\&G researchers produced multiple responses. Katz, Gurevitch, and Haas (1973) assembled a comprehensive list of social and psychological needs said to be satisfied by exposure to mass media. Rosengren (1974), attempting to theoretically refine U\&G, suggested that certain basic needs interact with personal characteristics and the social environment of the individual to produce perceived problems and perceived solutions. Those problems and solutions constitute different motives for gratification behavior that can come from using the media or other activities. Together media use or other behaviors produce gratification (or nongratification) that has an impact on the individual or society, thereby starting the process anew. Seeking to more closely define the relation between psychological motives and communication gratifications, Palmgreen and Rayburn (1979) studied viewers' exposure to public television and concluded that the U\&G approach served well as a complement to other determinant factors such as media availability, work schedules, and social constraints. Palmgreen and Rayburn argued that the primary task facing media researchers was to "integrate the roles played by gratifications and other factors into a general theory of media consumption" (p. 177). Essentially, Palmgreen and Rayburn were responding to earlier researchers' (Greenberg, 1974; Lometti et al., 1977) call to investigate gratification sought and gratifications re- 
ceived. Blumler (1979) identified three primary social origins of media gratifications: normative influences, socially distributed life changes, and the subjective reaction of the individual to the social situation. Also, in response, McLeod, Bybee, and Durall (1982) theoretically clarified audience satisfaction by concluding that gratifications sought and gratifications received were two different conceptual entities that deserved independent treatment in any future $U \& G$ research.

Another related theoretical development was the recognition that different cognitive or affective states facilitate the use of media for various reasons, as predicted by the U\&G approach. Blumler (1979) proposed that cognitive motivation facilitated information gain and that diversion or escape motivation facilitated audience perceptions of the accuracy of social portrayals in entertainment programming. In related research, McLeod and Becker (1981) found that individuals given advanced notice that they would be tested made greater use of public affairs magazines than did a control group. Bryant and Zillmann (1984) discovered that stressed individuals watched more tranquil programs and bored participants opted for more exciting fare.

\section{S AND 1990S RESEARCH}

Rubin (1983) noted that gratifications researchers were beginning to generate a valid response to critics. He concluded that his colleagues were making a systematic attempt to (a) conduct modified replications or extensions of studies, (b) refine methodology, (c) comparatively analyze the findings of separate investigations, and (d) treat mass media use as an integrated communication and social phenomenon. Examples include Eastman's (1979) analysis of the multivariate interactions among television viewing functions and lifestyle attributes, Ostman and Jeffers's (1980) examination of the associations among television viewing motivations and potential for lifestyle traits and television attitudes to predict viewing motivations, Bantz's (1982) exploration of the differences between general medium and specific program television viewing motivations and the comparability of research findings, Rubin's (1981) consideration of viewing motivations scale validity and the comparability of research results in U\&G research, and Palmgreen and Rayburn's (1985) empirical comparison of alternative gratification models.

Likewise, Windahl (1981) also sought to advance U\&G theoretically. In his "Uses and Gratifications at the Crossroads," he argued that the primary difference between the traditional effects approach and the U\&G approach is that a media effects researcher usually examines mass communication from the perspective of the communicator, whereas the $U \& G$ researcher uses the audience as a point of departure. Believing it was more beneficial to emphasize similarities than differences, Windahl coined the term conseffects and argued for a synthesis of the two approaches. Thus, he suggested, observations that are partly results of content use in itself and partly results of content mediated by use would serve as a more useful per- 
spective. Windahl's approach served to link an earlier U\&G approach to more recent research.

Aspiring to heighten the theoretical validity of structural determinants, Webster and Wakshlag (1983) integrated the dissimilar perspectives of U\&G and "models of choice," attempting to locate the interchange between programming structures, content preferences, and viewing conditions in the program choice process. Likewise, Dobos (1992), using U\&G models applied to media satisfaction and choice in organizations, predicted television channel choice and satisfaction within specific communication technologies.

\section{ACTIVE AUDIENCE}

Also, in the 1980s, researchers reevaluated the long-held notion of an active audience. During this time, some researchers reiterated that although both uses and effects sought to explain the outcomes or consequences of mass communication, they did so by recognizing the potential for audience initiative and activity (Rubin, 1994b). Levy and Windahl (1984) attempted to articulate a theoretically more complete notion of audience activity and to test a model of audience orientations that linked activity to U\&G, and Rubin (1984) suggested that audience activity is not an absolute concept, but a variable one. Notably, Windahl (1981) argued that "the notion of activeness leads a picture of the audience as superrational and very selective, a tendency which invites criticism" (p. 176). Instead, he argued audience activity covers a range of possible orientations to the communication process, a range that "varies across phases of the communication sequence" (Levy \& Windahl, 1984, p. 73). More succinctly, different individuals tend to display different types and amounts of activity in different communication settings and at different times in the communication process.

In support of this, theoretical active audience models have increasingly emerged that range from high audience activity to low levels of involvement. For example, both dependency and deprivation theories suggest that some individuals under certain conditions such as confinement to home, low income, and some forms of stress form high levels of attachment to media. These include television (Grant, Guthrie, \& Ball-Rokeach, 1991), newspapers (Loges \& Ball-Rokeach, 1993), and communication technologies such as remote control devices (Ferguson \& Perse, 1994).

\section{DEPENDENCY THEORY}

Media dependency theory itself posits that media influence is determined by the interrelations between the media, its audience, and society (DeFleur \& Ball-Rokeach, 1982). The individual's desire for information from the media is the primary variable in explaining why media messages have cognitive, affective, or variable effects. Media dependency is high when an individual's goal satisfaction relies on in- 
formation from the media system (Ball-Rokeach, 1985). Rubin and Windahl (1986) augmented the dependency model to include the gratifications sought by the audience as an interactive component with media dependency. For Rubin and Windahl, the combination of gratifications sought and socially determined dependency produced media effects. They argued that dependency on a medium or a message results when individuals either intentionally seek out information or ritualistically use specific communication media channels or messages. For example, McIlwraith (1998) found that self-labeled "TV addicts" often used television to distract themselves from unpleasant thoughts, to regulate moods, and to fill time. This link between dependency and functional alternatives illustrates how $U \& G$ is a theory "capable of interfacing personal and mediated communication” (Rubin, 1994b, p. 428).

\section{DEPRIVATION THEORY}

Deprivation theory has an even longer history in $U \& G$ research than dependency theory. Berelson (1949) studied the effects of the 1945 strike of eight major New York City daily newspapers on audience behavior. Since that time, additional studies of media strikes have emerged: Kimball (1959) replicated Berelson's study during the 1958 New York City newspaper strike; de Bock (1980) studied the effects of newspaper and television strikes in the Netherlands in 1977; Cohen (1981) examined a general media strike; and Walker (1990) analyzed viewers' reactions to the 1987 National Football League players' strike.

Related, Windahl, Hojerback, and Hedinsson (1986) suggested that the consequences of a media strike for adolescents were connected to the total degree of perceived deprivation of television as well as the specific content such as entertainment, information, and fiction. These deprivations are related both to media variables like exposure, involvement, and motives, and nonmedia variables such as socioconcept orientation and activities with friends and parents. Windahl et al. found that individuals in more socially oriented environments tended to feel more deprived than those in conceptually oriented settings.

\section{THEORIES OF LOW-LEVEL AND VARIABLE AUDIENCE ACTIVITY}

Conversely, other factors such as (a) different time relations (advance expectations, activity during the experience, postexposure), (b) variability of involvement (as background noise, companionship), and (c) ritualistic or habitual use (as mild stimulation) suggest a much less active audience than traditionally believed. Specifically, time relations theory argues that individuals are differentially selective and goal directed at different times: before, during, and after exposure to media (Levy \& Windahl, 1984). For example, Lemish (1985) discovered that college students arranged their busy schedules to view a specific soap opera, formed pro- 
gram-centered groups, paid attention to the program, and discussed the content with others.

Variability of involvement suggests that the motivation to use any mass medium is also affected by how much an individual relies on it (Galloway \& Meek, 1981), and how well it satisfies her or his need (Lichtenstein \& Rosenfeld, 1983). Thus, many $U \& G$ researchers have included some aspect of expectancy in their models and have turned to established theories of expectancy to explain media consumption (Rayburn, 1996). Rayburn cited Fishbein and Ajzen's (1975) expectancy value theory as illustrative. Fishbein and Ajzen's model poses three beliefs: (a) Descriptive beliefs result from direct observation of an object, (b) informational beliefs are formed by accepting information from an outside source that links certain objects and attributes, and (c) inferential beliefs are about the characteristics of objects not yet directly observed, or that are not directly observable. Palmgreen and Rayburn (1982) developed an expectancy model that successfully predicted gratifications sought from television news. Rayburn and Palmgreen combined U\&G with expectancy value theory to generate an expectancy value model of gratifications sought (GS) and gratifications obtained (GO).

For example, a study about talk radio by Armstrong and Rubin (1989) concluded that individuals who called in found face-to-face communication less rewarding, were less mobile, believed talk radio was more important to them, and listened for more hours a day than listeners who did not call in.

In terms of ritualistic and habitual media use, audience activity involves the concept of utility, an individual's reasons and motivations for communicating, but little intentionality or selectivity (Blumler, 1979; Hawkins \& Pingree, 1981). Rubin (1984) suggested that ritualized viewing involved more habitual use of television for diversionary reasons and a greater attachment with the medium itself. Instrumental viewing, on the other hand, reflected a more goal-oriented use of television content to gratify information needs or motives. Notably, however, Rubin (1984) cautioned that ritualized and instrumental media use are not neatly dichotomous but are more likely interrelated. Just as audience activity is variable, individuals may use media ritualistically or instrumentally depending on background, time, and situational demands. Thus, Perse and Rubin (1988) suggested a multidimensional view of audience activity, reinforcing an emphasis on media use instead of media exposure. Additionally, Rubin (1994a) argued that U\&G research needed to "continue its progression from simple exposure explanations of effects and typologies of media motivation to conceptual models that explain the complexity of the media effects process" (p. 103).

\section{ATTEMPTS TO REFINE U\&G}

Paradoxically, U\&G scholars may have been their own toughest critics. Throughout the decades, U\&G researchers challenged their own model and ar- 
gued for a more comprehensive theoretical grounding (Klapper, 1963; Rubin, 1994a; Schramm et al., 1961). Rubin (1986) called for a clearer picture of the relation between media and personal channels of communication and sources of potential influence. Swanson (1987) urged that research focus on three areas: the role of gratification seeking in exposure to mass media, the relation between gratification and the interpretive frames through which audiences understand media content, and the link between gratifications and media content. Windahl (1981) argued that a synthesis of several viewpoints would be most productive: (a) that media perceptions and expectations guide people's behavior; (b) that besides needs, motivation is derived from interests and externally imposed constraints; (c) that there are functional alternatives to media consumptions; and (d) that media content plays an important role in media effects. Rubin (1994b) agreed that a fruitful direction was a synthesis between $U \& G$ and media effects research as proposed by Windahl.

\section{CONTINUED CRITICISMS OF U\&G}

Thus, during the last several decades, U\&G researchers have continued to conceptually refine their perspective. Nevertheless, critics such as Stanford (1983) have assailed perceived deficiencies such as the confusing of operational definitions and the analytical model, a lack of internal consistency, and a lack of theoretical justification for the model offered. Stanford complained, "the discussion ranges far from the results, which do not support their theoretical underpinnings" (p. 247). Likewise, media hegemony advocates have contended that the $\mathrm{U} \& \mathrm{G}$ theory overextends its reach in asserting that people are free to choose the media fare and interpretations they want (White, 1994). J. A. Anderson (1996) conceded that $U \& G$ is an "intelligent splice of psychological motivations and sociological functions, [but nonetheless noted that] materialism, reductionism, and determinism, as well as foundational empiricism, are all firmly in place" (p. 212).

Thus, much contemporary criticism of U\&G challenges assumptions that include (a) media selection initiated by the individual; (b) expectations for media use that are produced from individual predispositions, social interaction, and environmental factors; and (c) active audiences with goal-directed media behavior (Wimmer \& Dominick, 1994).

Outside of the United States, particularly in non-Western countries, even a diffused notion of an active audience has limited acceptability and U\&G scholars differ in their methodological approach. For example, Cooper (1997) noted that Japan's communication researchers view media's individual-level impact as a limited effects perspective, in that media serve only to reinforce preexisting attitudes and behaviors. 


\section{CONTINUED FLAWS IN U\&G THEORY}

Thus, despite attempts to produce a more rigorous and comprehensive theory, several flaws continue to plague the perspective, and U\&G researchers have acknowledged this. First, by focusing on audience consumption, U\&G is often too individualistic (Elliott, 1974). It makes it difficult to explain or predict beyond the people studied or to consider societal implications of media use. Second, some studies are too compartmentalized, producing separate typologies of motives. This hinders conceptual development because separate research findings are not synthesized. Third, there still exists a lack of clarity among central concepts such as social and psychological backgrounds, needs, motives, behavior, and consequences. Fourth, $\mathrm{U} \& \mathrm{G}$ researchers attach different meanings to concepts such as motives, uses, gratifications, and functional alternatives, contributing to fuzzy thinking and inquiry. Fifth, the cornerstones of $U \& G$ theory, the notion of an active audience and the validity of self-report data to determine motives, are assumed by researchers, and that assumption may be "a little simplistic or naive" (Severin \& Tankard, 1997, p. 335). Thus, some critics continue to argue that traditional U\&G methodologies, particularly those dependent on self-reported typologies and relying on interpretation of lifestyle and attitude variables rather than observable audience behavior, are suspect (Rosenstein \& Grant, 1997). Self-reports may not be measuring the individual's actual behavior so much as his or her awareness and interpretation of the individual's behavior. This dilemma is further complicated by evidence that suggests that individuals may have little direct introspective access to the higher order cognitive processes that mediate their behavior (Nisbett \& Wilson, 1977), and therefore may base their self-reports on "a priori, casual theories influenced by whatever stimuli happen to be salient" (Rosenstein \& Grant, 1997, p. 4).

\section{U\&G THEORY BUILDING}

Despite these perceived theoretical and methodological imperfections, I would argue that reproach of $U \& G$ must be tempered with encouragement. A typology of uses, although not providing what some scholars would consider a refined theoretical perspective, furnishes a benchmark base of data for other studies to further examine media use. Furthermore, Finn (1997) suggested that due to a contemporary preference for more parsimonious models of human personality, the design of $\mathrm{U} \& \mathrm{G}$ studies committed to a "broad range of personality traits has become a more tractable endeavor" (p. 1). For example, current scholars favor a typology of five (K. J. Anderson \& Revelle, 1995; Costa \& McCrae, 1988), and in some cases as few as three fundamental personality traits (Eysenck, 1991). Contrast this to the earlier system of 16 primary personality factors as advanced by Cattell, Edger, and Tatsuoka (1970) and McGuire (1974). 
Second, there has been a trend toward enlarging and refining theories concerning affective motivations toward media use (Finn, 1997). For instance, Finn noted that the rigid dichotomy between instrumental and ritualistic behaviors that formerly esteemed information-seeking over entertainment-seeking behaviors has been infused with new motivational theories. These take into consideration the individuals' need to manage affective states (D. R. Anderson, Collins, Schmitt, \& Jacobvitz, 1996; Kubey \& Csikszentmihalyi, 1990) or achieve optimum levels of arousal (Donohew, Finn, \& Christ, 1988; Zillmann \& Bryant, 1994).

Third, fully focusing on the social and cultural impacts of new communication technologies may be premature until we grasp more fully how and why people are making use of these media channels (Perse \& Dunn, 1998). It stands to reason that in the information age, media users will seek information. Equally reasonably, World Wide Web (Web) survey respondents are most attracted to information formats that speak to them in a more personalized voice and in a broader entertaining context (Eighmey \& McCord, 1995).

Thus, the media uses and effects process is an increasingly complex one that requires careful attention to antecedent, mediating, and consequent conditions (Rubin, 1994b). A continued emphasis on theory building must proceed, particularly by scholars who will attempt to develop theories that explain and predict media consumption of the public based on sociological, psychological, and structural variables. Some current research illustrates the plausibility of changing the scope of U\&G research from an "exaggerated emphasis on using mass media to meet social deficits, to the function it fulfills," as Blumler (1985, p. 41) previously suggested to aiding people in promoting social identities (Finn, 1997). A serious potential problem facing $U \& G$ researchers, however, may be the practical impossibility of probability sampling on the Internet. At this point, studies may only be able to tentatively generalize to a very specific population. Also, Web-administered surveys may pose problems with tracking precise and reliable response rates. Additionally, a current lack of standardization among browsers, servers, and operating systems may create a serious challenge to methodically sound quantitative research. However, as we invent more sophisticated methods of tracking users and become more familiar with their demographics, generalizability to well-studied segments of the overall population should become less problematic (Smith, 1997).

\section{TELECOMMUNICATIONS TECHNOLOGY AND THE REVIVAL OF U\&G}

U\&G fell out of favor with some mass communication scholars for several decades, but the advent of telecommunications technology may well have revived it from dormancy. The deregulation of the communications industry and the 
convergence of mass media and digital technology have altered the exposure patterns of many media consumers (Finn, 1997). Improved compression algorithms now allow for the compression of video data for online transmission down telephone copper wire, coaxial, fiber optic cable, and by broadcast satellite, cellular, and wireless technologies (Chamberlain, 1994, p. 279). As new technologies present people with more and more media choices, motivation and satisfaction become even more crucial components of audience analysis. Not surprisingly, researchers have been busy applying U\&G theory to a wide range of newly popularized video media technologies. For example, Donohew, Palmgreen, and Rayburn (1987) explored how the need for activation interacts with social and psychological factors to affect media U\&G sought by cable television audiences. They identified four lifestyle types whose members differed significantly on a wide range of variables, including newspaper and newsmagazine readership and gratifications sought from cable television. They found that individuals with a high need for activation had lifestyles involving greater exposure to media sources of public affairs information than individuals with a lower need for activation and less cosmopolitan lifestyles. LaRose and Atkin (1991) also examined cable subscribership in U.S. households, including the factors that lead to initial subscription and to subscription retention. Walker and Bellamy (1991) related television remote control devices to audience member interest in types of program content. Lin (1993) conducted a study to determine if VCR satisfaction, VCR use, and interpersonal communication about VCRs were related to three functions: home entertainment, displacement, and social utility. James, Wotring, and Forrest (1995) investigated adoption and social impact issues possessed by the characteristic bulletin board user and how board use affected other communication media. Jacobs (1995) examined the relation between sociodemographics and satisfaction by studying the determinants of cable television viewing satisfaction. Jacobs identified antecedents in the study that included performance attributes, complaint call frequencies, and cable system characteristics. Funk and Buchman (1996) explored the effects of computer and video games on adolescents' self-perceptions. Perse and Dunn (1998) examined home computer use, and how CD-ROM ownership and Internet capability were linked to computer utility. Each of these scholars questioned whether new telecommunications media are used to satisfy the same needs they had been theorized to satisfy with traditional communication media (Williams, Phillips, \& Lum, 1985). For example, the parasocial aspects of television soap opera viewing may soon pale in comparison to the interactive relation possibilities offered by electronic chat rooms and multiuser domains. Researchers are now being challenged to "decode the uses and gratifications of such communication experiences” (Lin, 1996, p. 578).

This increasing interest by communication scholars in online audiences may be particularly intense because of the makeup of these newer media forms: interactive 
media obscure the line between the sender and receiver of mediated messages (Singer, 1998). Furthermore, new media like the Internet possess at least three attributes of data not commonly associated with traditional media: interactivity, demassification, and asynchroneity.

\section{INTERACTIVITY}

Interactivity significantly strengthens the core $U \& G$ notion of active user because it has been defined as "the degree to which participants in the communication process have control over, and can exchange roles in their mutual discourse" (Williams, Rice, \& Rogers, 1988, p. 10). Communication literature reflects six user-oriented dimensions of interactivity that should be useful for the U\&G approach: threats (Markus, 1994), benefits (S. Ang \& Cummings, 1994), sociability (Fulk, Flanagin, Kalman, Monge, \& Ryan, 1996), isolation (Dorsher, 1996), involvement (Trevino \& Webster, 1992), and inconvenience (Stolz, 1995; Thomas, 1995). Additionally, Ha and James (1998) cited five dimensions of interactivity: playfulness, choice, connectedness, information collection, and reciprocal communication. Ha and James suggested that for "self-indulgers" and "Web surfers," the playfulness and choice dimensions of interactivity fulfill self-communication and entertainment needs. For task-oriented users, the connectedness dimension fulfills information needs. For expressive users, the information collection and reciprocal communication dimensions allow them to initiate communication with others of common online interests. Ha and James assessed dimensions such as information collection and reciprocal communication as higher levels of interactivity. Playfulness, choice, and connectedness were viewed as lower levels of interactivity.

Heeter (1989) also defined interactivity as a multidimensional concept: amount of choice provided to users, amount of effort a user must exert to access information, how actively responsive a medium is to users, potential to monitor system use, degree to which users can add information to the system that a mass undifferentiated audience can access, and degree to which a media system facilitates interpersonal communication between specific users.

Thus, the real advantage to interactivity for individual users is not simply multimedia videos, online shopping, or obtaining information on demand. Just as the Lotus 1-2-3 spreadsheet allowed users to create their own business plans and models, interactivity may offer users the means to develop new means of communication (Dyson, 1993) and greatly increase user activity. After all, interactivity is not only the ability to select from a wide array of Internet merchandise or "surf" 500 or more television channels. Technologists such as Nelson (1990) argued that human-computer activities represent the human impulse to create interactive representation. Dutton, Rogers, and Jun (1987) suggested that interactivity displays "the degree to which the new communication systems are capable of responding to user commands" (p. 234). However, interactivity, at least on the Internet with current tech- 
nology, does pose some serious practical limitations for users. The ability to access information is limited to three means: entering the address of a location the user already knows, scrolling through a single document, and following a hypertext link (Jackson, 1997). A further serious downside to interactivity continues to exist. More and more often, a Web search using a keyword or a hypertext link results in an extensive list and the user must choose from hundreds or even thousands of destinations, often with few or no contextual clues (Bergeron \& Bailin, 1997).

\section{DEMASSIFICATION}

Williams et al. (1988) defined demassification as the control of the individual over the medium, "which likens the new media to face-to-face interpersonal communication" (p. 12). Demassification is the ability of the media user to select from a wide menu. Chamberlain (1994) argued that we have entered an era of demassification in which the individual media user is able, through newer technologies, to pick from a large selection of media, previously shared only with other individuals as mass media. Unlike traditional mass media, new media like the Internet provide selectivity characteristics that allow individuals to tailor messages to their needs. Kuehn (1994) cited The New York Times as an example. Those who wish to receive the paper version of The New York Times must pay for the whole paper, whereas those receiving the electronic version may select only those articles of interest to them. Mass messages will be able to be viewed as second-class by recipients and "individual, one-on-one dialogue will be the preferred mode of communication" (Chamberlain, 1994, p. 274).

\section{ASYNCHRONEITY}

Asynchroneity refers to the concept that messages may be staggered in time. Senders and receivers of electronic messages can read mail at different times and still interact at their convenience (Williams et al., 1988). It also means the ability of an individual to send, receive, save, or retrieve messages at her or his convenience (Chamberlain, 1994). In the case of television, asynchroneity meant the ability of VCR users to record a program for later viewing. With electronic mail (e-mail) and the Internet, an individual has the potential to store, duplicate, or print graphics and text, or transfer them to an online Web page or the e-mail of another individual. Once messages are digitized, manipulation of media becomes infinite, allowing the individual much more control than traditional means.

For U\&G researchers, each of these accelerated media aspects-interactivity, demassification, and asynchroneity — offer a vast continuum of communication behaviors to examine. 


\section{TRADITIONAL MODELS OF U\&G}

Rogers (1986) concluded that these novel attributes make it nearly impossible to investigate the effects of a new communication system using earlier research. Rogers argued that "conventional research methodologies and the traditional models of human communication are inadequate. That's why the new communication technologies represent a new ball game for communication research" (p. 7).

Other mass media scholars, however, suggested that traditional models of U\&G may still provide a useful framework from which to begin to study Internet and new media communication (December, 1996; Kuehn, 1994; Morris \& Ogan, 1996). All four of these scholars contend that a U\&G model provides a productive method of examining Internet use at this time. Much of the current activity on the Web involves exploratory behavior, offering an environment in which users can contact thousands of sources, find information presented in a wide range of formats, and interact with many of the sources they contact (Eighmey, 1997). Kuehn (1994) emphasized this interactive capacity of computer-mediated communication and suggested a group of U\&G statements be used as rating scales to evaluate computer-aided instructional programs. His typology included convenience, diversion, relationship development, and intellectual appeal.

For December (1996), more traditional typologies of mass media consumption translate appropriately to the Internet. U\&G researchers can continue to use categories such as surveillance, entertainment and diversion, interpersonal utility, and parasocial interaction to test people's attitudes toward media consumption through such variables as GO and GS. Also in line with previous U\&G scholars, Morris and Ogan (1996) argued that the concept of active audience, whether instrumental or ritualized, should continue to be included in current and future Internet research.

Perse and Dunn (1998) also suggested that U\&G offers a convincing theoretical explanation for changes in media use patterns following the adoption of new communication technologies such as personal computers. Because they are increasingly filling similar needs, personal computers may be displacing the use of traditional media like newspapers and television. When television was adopted, for instance, it tended to replace other entertainment activities such as radio, movies, and comics. A more recent study concluded that displacement of other media and forms of television occurred with an individual's acquisition of a VCR (Anonymous, 1989). Significantly, some predict that television, the Internet, and the telephone may soon merge into one instrument, displacing other media choices.

\section{TWO THEORETICAL DICHOTOMIES}

In general, although the media industry is based on the strategy that audiences are at least somewhat active, two dichotomies concerning media and $U \& G$ research have long prevailed (Zillman \& Bryant, 1985). In the first group are those scholars who 
view the mass audience as predominantly passive and those who hold that audience members are active and discriminating. In the second group are those studies that underscore the explanatory power of individual characteristics and those that attribute power to structural factors (Cooper, 1996).

Those scholars that supported a passive audience conception often cite the escapist model of media use, particularly in television viewing (Stone \& Stone, 1990). The escapist model presumes that television viewing consists largely of a leisurely way to pass the time (Barwise, Ehrenberg, \& Goodhardt, 1982; Kubey, 1986) and that television programming is primarily homogeneous in gratifying a time-filling behavior (McQuail, Blumler, \& Brown, 1972). Goodhardt, Ehrenberg, and Collins's (1987) study of British television audience behavior is frequently cited as corroboration that audience availability, not selectivity, is paramount in shaping patterns of viewing. In their study, the researchers examined three variables: repeat viewing, audience duplication, and audience appreciation. They discovered that (a) 55\% of the viewers of one episode of a television program also watched the following episode; (b) for any two programs, the level of audience viewing duplication depends on the programs' ratings and not their content; and (c) a viewer's average appreciation score does not depend on the program's rating or its incidence of repeat viewing. Goodhardt et al. concluded that television viewing behavior and audience appreciation appeared to follow "a few very general and simple patterns" (p. 116) rather than involving great differentiation between distinct groups of viewers and between the audiences of different programs. Horna (1988) found specific relations between leisure and an individual's $U \& G$ of mass media. Specifically, the majority of media audiences are seeking entertainment, relaxation, or escape, and for most people, leisure and mass media are nearly synonymous.

Conversely, a chief tenet of $U \& G$ theory of audience behavior is that media use is selective and motivated by rational self-awareness of the individual's own needs and an expectation that those needs will be satisfied by particular types of media and content (Katz et al., 1974). Rubin (1983) argued that "viewing motivations are not isolated static traits, but rather, comprise a set of interactive needs and expectations" (p. 39). Studies by scholars such as Garramone $(1984,1985)$ suggested that motivation leads to higher knowledge regardless of attention to a specific medium. Other studies that support the active audience assumption include work by Fry and McCain (1983), who found that a person's expectations, evaluations, and motivations determined the usefulness of a medium; and work by Gandy, Matabane, and Omachonu (1987), who discovered that the strongest factors predicting knowledge from a medium were an individual's gender and personal interest in the issues. Furthermore, Grunig (1979) suggested that people sometimes seek media content that has a functional relation to situations in which they are involved. Perse and Courtright (1993) concluded that individuals are aware of communication alternatives and select channels based on the normative images those channels are perceived to have. 


\section{STRUCTURAL MODELS OF U\&G}

On the other hand, those scholars who attribute media use behavior to structural factors, particularly in television viewing, have used complex statistical procedures to show that channel loyalty, inheritance effects, repeat viewing, and availability are stronger predictors of program choice than any measure of program typology (Goodhardt et al., 1987; Webster \& Wakshlag, 1983). Supporting this perspective, in Heeter's (1989) study of program choice and channel selection, $23 \%$ of all respondents were unable to identify what channels they commonly viewed. Structural scholars interpret this to mean that most audience members pay little attention to content or channel but use television in a relatively undiscriminating fashion. A viewer's primary relation may be with the medium itself rather than with any specific channel or program (Rosenstein \& Grant, 1997). This has serious ramifications, particularly for critical scholars, who argue that "new media technologies will be funded almost exclusively by private enterprise" (Chamberlain, 1994, p. 280). This will restrict the use of the latest technology to those who can afford it, widening the gap between the haves and have nots, perpetuating information-rich and information-poor individuals, groups, and societies.

Despite their usefulness, however, most structural models should be viewed as "a set of complex, surrogate variables that can have great predictive power" (Cooper, 1996, p. 10) but lack ability to explain the underlying processes. Research has yet to fully explicate how the structure of television program offerings, for example, influence the actual choices made by individual viewers. Thus, U\&G continues to be exceedingly useful in explaining audience activity when individuals are most active in consciously making use of media for intended purposes. For example, Lind's (1995) study concluded that television viewers did not want their news fare limited by the government, the industry, or even concerned viewers.

\section{NEWER COMMUNICATION MEDIA}

Additionally, the active audience concept is gaining credibility with newer media researchers. As emerging technologies provide users with a wider range of source selection and channels of information, individuals are selecting a media repertoire in those areas of most interest. Heeter and Greenburg (1985) suggested that given the many entertainment options on cable television, most viewers choose a subset of channels, or a repertoire, that they prefer. Ferguson (1992) discovered that the main component of television channel repertoire was whether the viewer subscribed to cable television. Atkin (1993) identified the phenomenon of repertoire when studying the interrelations between cable and noncable television, and subscriptions to them by owners of VCRs, camcorders, personal computers, walkman radios, and cellular telephones. Reagan (1996) argued that each individual is now able to rely on easy-to-use media for low-inter- 
est topics and more complex repertoires for higher interest topics. He suggested that researchers should move away from labeling media users as television oriented or newspaper oriented, and consider them more as users of "cross-channel clusters of information sources" (p. 5).

Similarly, some communications scholars are viewing the Internet as the ultimate in individualism, "a medium with the capability to empower the individual in terms of both the information he or she seeks and the information he or she creates" (Singer, 1998, p. 10). Inversely, others see the Web as the ultimate in community building and enrichment, through which users can create relationships online in ways that have never been possible through traditional media. Despite this optimistic portrait, Rafaeli (1986) speculated that computer-mediated communication by individuals may lead to loneliness and isolation. Moreover, Young (1996) raised concern that excessive use of new media such as the personal computer may leave users vulnerable to technological dependencies like "Internet addiction."

Whatever the approach, most U\&G scholars agree that concepts such as active and audience will have to be revised when applied to Internet communication. Reasons for using the Internet differ from person to person. Some individuals are goal directed and may want to complete a task through visiting specific Web sites. Others may only be curious and surf the Web for fun. Additionally, in electronic discussion groups, for example, some users are quiet observers and "lurkers" who never participate, whereas others frequently participate in the discussion (Ha, 1995). Fredin and David (1998) argued that audience activity, as it applies to hypermedia use, has three interrelated components that place elevated demands on individual user interaction. First, hypermedia obligate frequent audience responses because, unlike radio or television, hypermedia freeze or halt if responses are not made. Second, the audience is presented with a seemingly unending variety of options from which they must choose. Third, an individual's choices are often highly contingent on a series of earlier responses. Moreover, differences in quality and quantity of activity exist among individual online users. Sundar (1998) contended that experienced Internet users make different choices than do novices, particularly in matters such as attentiveness to sources in electronic news stories.

\section{THE INTERNET AND U\&G}

Additionally, some media scholars argued that even the traditional audience concept must be radically amended because of novel informational characteristics of the Internet. Abrahamson (1998) envisioned the Internet moving from a mass-market medium to a "vehicle for the provision of very specific high-value information to very specific high-consumption audiences" (p. 15). Specifically, he theorized a mass Internet audience "fractionated" into smaller, more elite audiences, such as occurred with consumer magazines in the 1960s. Ha and James (1998) believed the 
medium will evolve from a mass-produced and mass-consumed commodity to an "endless feast of niches and specialties" (p. 2). Weaver (1993) forecasted a tiered communication system emerging, with some messages reaching the masses (presidential speeches, war coverage), others reaching a significant segment of society (business news, some sporting events), and others reaching relatively small, special-interest groups (music, art, and hobbies). Dicken-Garcia (1998) envisioned common interests rather than geographic space defining much of the Internet audience. Yet, she asserted, the Internet, unlike other media, has no targeted community as a primary audience or as a result of its function.

Other scholars have insisted that the traditional audience concept must be modified because of the interpersonal potential of the Internet. Ironically, interpersonal relationships, one of the two mediating variables of the early persuasion model (selectivity being the other), and the forerunner of diffusion of innovations, is reemerging as a serviceable U\&G variable. This concept of "personalness," social presence, or the degree of salience in interpersonal relationships is being explored increasingly by $U \& G$ researchers, particularly in relation to interactivity. Cowles (1989) found that interactive media (teletext and videotext) possessed more personal characteristics than noninteractive electronic media. She predicted media gratifications theory is ripe for future research involving new media and that such research "might best occur within the context of an individual's total media environment" (p. 83). Dicken-Garcia (1998) contended that the Internet places stronger emphasis on informal, interpersonal conversation than has been true of earlier media. A notable and novel characteristic of Internet audience behavior according to Dicken-Garcia lies in the phenomenon that users communicate electronically what they might never say in person or on the phone. Internet users sometimes take on new personalities, ages, and genders, all of these exemplified by less inhibited behavior. She also noted that Internet talk more resembles word of mouth than newspapers and television, and that, often, "users unquestionably accept information via the Internet that they would not accept so readily from another medium" (p. 22).

The Internet may also have important ramifications for the communication gratifications traditionally sought by consumers of news information. The news, particularly as provided by traditional media institutions, has been linked with the creation of an informed electorate in areas including politics and international events, and to the perpetuation of a democratic society (Wenner, 1985).

What Dunleavy and Weir (1998) called open-book government could also form a significant part of a new era of electronic democracy. Not only does the Internet have the potential to improve access to the government, it could also invigorate representative democracy:

Electronic advances could make public consultation and participation wider, easier and more diverse; and provide new media opportunities which could both focus and diversify the information people receive and obtain for themselves, as the old media 
fragment into more and more apolitical and specialised forms - sports channels, gardening channels, fashion channels, golf channels and so on. (p. 72)

As an example, Dunleavy and Weir (1998) cited the British Broadcasting Company's Election 97 Web site, which on election night recorded more than 1.5 million hits. During the election, the Web site not only provided far more reliable basic information than any conventional mass media source, it also allowed individuals to e-mail queries and get answers. Political experts were shocked by the quality of the questions submitted, the insights they contained, and the appetite for information. Party policies, opinion polls, electoral trajectories, and key issues were clarified and debated in depth.

The Internet may also greatly benefit in the creation of a vibrant "discursive democracy" (Dunleavy \& Weir, 1998). Government departments, local councils, and other public bodies can clarify how they sculpt their policies and request interested citizens and specialists to participate directly in determining them.

Interactive question-and-answer sessions, policy forums, panels and discussion groups, planning consultations, chat-lines, even tabloid-style votes can all generate a great deal more information that policymakers should consider. They could also give far more in-depth information more cheaply and conveniently, respond to people's questions and ideas and encourage the public to submit proposals for action. (p. 2)

Newhagen and Rafaeli (1996) also attempted to theoretically position the Internet as a legitimate subject of mass communication and social science research and they called for a U\&G approach to investigate the medium. They suggested that because a tradition in mass communication research of studying $U \& G$ already exists, that approach may be useful in laying out a taxonomy of cyberspace. Newhagen and Rafaeli focused on five defining characteristics of communication on the Internet: multimedia, packet switching, hypertextuality, synchroneity, and interactivity.

Besides synchroneity and interactivity, which have already been discussed, the other three properties deserve closer explanation. Multimedia is the use of computers to present text, graphics, video, animation, and sound in an integrated way. Long extolled as the future revolution in computing, multimedia applications were, until the mid-1990s, scarce due to the costly hardware required. With increases in performance and decreases in price, multimedia is now ubiquitous. Nearly all current personal computers are capable of displaying video, although the resolution available depends on the power of the computer's video adapter and central processing unit. Because of the storage demands of multimedia applications, the most effective media are CD-ROMs, and now Zip ${ }^{\mathrm{TM}}$ disks, which both contain far greater memory capacity than traditional floppy disks. 
Packet switching refers to protocols in which messages are divided into packets before they are sent. Each packet is then transmitted individually and can even follow different routes to its destination. Once all the packets forming a message arrive at the destination, they are recompiled into the original message. In contrast, normal telephone service is based on a circuit-switching technology, in which a dedicated line is allocated for transmission between two parties. Circuit switching is ideal when data must be transmitted quickly and must arrive in the same order in which it is sent. This is the case with most real-time data, such as live audio and video. Packet switching is more efficient and robust for data that can withstand some delays in transmission, such as e-mail messages and Web pages (Newhagen \& Rafaeli, 1996).

Hypertextuality, which constitutes the core of Internet documents, is created by the simple hypertext markup language (HTML), so that the text represents not a fixed linear sequence, but performs as a network to be actively composed (Sandbothe, 1996). Every building block of text (node) contains an abundance of keywords, pictograms, and pictures, which can be clicked on with a mouse; these are the links. Sandbothe (1996) predicted that hypertext technology already is having profound effects on the use of electronic texts:

Every reader lays his own trail in the text whilst reading. Or rather, every reader composes the object he reads through the active selection of the links provided. The individual reception perspective determines the succession of text building blocks. Reading is no longer a passive process of reception, but rather becomes a process of creative interaction between reader, author, and text. (p. 2)

Additionally, many contemporary communication researchers seek to legitimize the Internet as a subject of research by framing a theoretical construct of the Internet as a continuum between mass and interpersonal communication. Similar questions appear to exist in the literature for both $U \& G$ and interpersonal communication. In both cases, the focus is on the biological, psychological, and sociological motivations behind people taking part in receiving or exchanging messages (Newhagen \& Rafaeli, 1996). For example, Rice and Williams (1984) argued that interactive new media have the ability to "co-locate with the interpersonal sources on one or both of the personal dimensions" (p. 65). Garramone, Harris, and Anderson (1986) suggested that social presence mediates the relation between the interactive use and noninteractive use of political computer bulletin boards. Garrison (1995) adopted U\&G to quantify a number of important questions about how and why journalists do computer-assisted reporting. Eighmey and McCord (1995) drew on the $U \& G$ perspective to examine the audience experience associated with Web sites. Thus, U\&G research may well play a major role in answering initial Web-use questions of prurience, curiosity, profit seeking, and sociability. U\&G also holds the prospect for understanding the Internet's mutability, or its broad 
range of communication opportunities, by "laying out a taxonomy of just what goes on in cyberspace" (Newhagen \& Rafaeli, 1996, p. 11).

\section{U\&G AND QUALITATIVE METHODOLOGIES}

Leeds-Hurwitz (1992) suggested that a revolution was occurring in all the fields that study human behavior, including communication. She cited specifically "cultural studies, critical theory, postmodernism, semiotics, phenomenology, structuralism, hermeneutics, naturalistic inquiry, ethnography and social communication" (p. 131). This led Weaver (1993) to sound a note of caution about dismissing quantitative methods. Weaver argued that many communication researchers have spent decades applying quantitative methods and statistical analysis. These methods have told us much about general patterns, trends, and relationships, and "can enable us to generalize with far more accuracy than can our own personal experiences and impressions" (p. 213). Additionally, Dobos (1992) concluded that the $U \& G$ approach should prove effective in ascertaining the importance of social context as a factor in the communication experience. Significantly, the way that individuals choose to use media differs accordingly with their position in the social structure (Roe, 1983; Rosengren \& Windahl, 1989).

Thus, it is important to remember that $U \& G$ theory continues to offer more than a methodological perspective. Dervin (1980) advocated that media planners and those conducting information campaigns should begin with the study of the potential information user and the questions that person is attempting to answer to make sense of the world. After all, Pool (1983) noted that when a medium is in the early stages of development, predictions are often inaccurate. Thus, the U\&G approach may serve as the vanguard of an eventual thorough quantitative and qualitative analysis of new media technologies.

This is not to relegate qualitative or interpretive methodologies to a subordinate role. On the contrary, Jensen and Jankowski (1991) suggested that quantitative methodologies could be used quite effectively to inform the more commonly used qualitative audience methodologies of interpretive media research. Different levels of analysis, including individual, small group, organizational, societal, and cultural, may require the use of multiple methods in single studies. Thus, communication researchers should be encouraged to employ U\&G more frequently in conjunction with qualitative methodologies in a holistic approach. One case of this is Schaefer and Avery's (1993) study of audience conceptualizations of the Late Night With David Letterman television show. The study used both questionnaires and interviews to "combine the strengths of survey data with the richness of depth interviews" (p. 271). Additionally, Massey (1995) used a ninefold U\&G typology to operationalize her qualitative study of audience media use during the 1989 Loma Prieta earthquake disaster. 
Newhagen and Rafaeli (1996) suggested that in time, questions at cultural and societal levels may offer the greatest contribution to communications research. For example, Morley's $(1980,1986,1992)$ studies of family TV viewing and domestic power in the working class, Radway's (1984) account of female empowerment linked to reading romance novels, I. Ang's (1985) analysis of Dutch women's interpretations and use of the international television series Dallas, Liebes and Katz's (1990) analysis of ethnic and cultural variation in Dallas audiences, and Lull's (1991) study of Chinese viewers' resistive engagements with television all document culturally and historically specific ways in which audiences actively interpret and use mass media (Lull, 1995). However, to truly understand new media technologies, critical scholars should learn to embrace multiple levels of analysis. Empiricists, on the other hand, Newhagen and Rafaeli argued, "will have to show a greater, more eclectic tolerance for experimental science" (p. 9).

\section{THEORETICAL SYNOPSIS OF U\&G}

More than a decade ago, after reviewing the results of approximately $100 \mathrm{U} \& \mathrm{G}$ studies, Palmgreen (1984) proclaimed that a complex theoretical structure was emerging. Palmgreen's statement has significance for contemporary and future mass communication researchers in at least two ways. First, he was proposing an integrative gratifications model that suggested a multivariate approach (Wimmer \& Dominick, 1994); that is, a commitment for researchers to investigate the relation between one or more independent variables and more than one dependent variable. He noted emergent research techniques such as hierarchical regression, canonical correlation, multiple classification analysis, and structural equation modeling to control for media exposure and other intervening variables (Rayburn, 1996). Second, Palmgreen was answering critics who had long argued that the U\&G perspective was more a research strategy or heuristic orientation than a theory (Elliott, 1974; Swanson, 1977; Weiss, 1976). He suggested that audience GS and GO were associated with a broad variance of media effects including knowledge, dependency, attitudes, perceptions of social reality, agenda setting, discussion, and politics (Rayburn, 1996).

Thus, if anything, one of the major strengths of the $U \& G$ perspective has been its capacity to develop over time into a more sophisticated theoretical model. Historically, the focus of inquiry has shifted from a mechanistic perspective's interest in direct effects of media on receivers to a psychological perspective that stresses individual use and choice (Rubin, 1994b). U\&G researchers have also moved from a microperspective toward a macroanalysis. Thus, although the microunit of data collection has primarily remained the individual, the focus of inquiry has been transformed over time. Interpretation of the individual's response by researchers has shifted from the sender to the receiver, from the media to the audience. The pri- 
mary unit of data collection of U\&G continues be the individual, but that individual's activity is now analyzed in a plethora of psychological and social contexts including media dependency, ritualization, instrumental, communication facilitation, affiliation or avoidance, social learning, and role reinforcement. U\&G research continues to typologize motivations for media use in terms of diversion (i.e., as an escape from routines or for emotional release), social utility (i.e., to acquire information for conversations), personal identity (i.e., to reinforce attitudes, beliefs, and values), and surveillance (i.e., to learn about one's community, events, and political affairs).

Furthermore, previous U\&G researchers have primarily concentrated on choice, reception, and manner of response of the media audience. A key assumption has been that the audience member makes a conscious and motivated choice among media channel and content (McQuail, 1994). Yet, recent U\&G researchers have even begun to question stock assumptions about the active audience concept. Although researchers continue to regard audience members as universally active, some now suggest that all audience members are not equally active at all times ( $\mathrm{Ru}-$ bin, 1994b). This assertiveness of U\&G researchers to continuously critique basic assumptions suggests a dynamic and evolving theoretical atmosphere, especially as we depart the industrial era for the postindustrial age.

\section{U\&G AS LEGITIMATE THEORY}

Perhaps endlessly, scholars will continue to debate which prevailing theories should be acknowledged as "legitimate" communication theories. U\&G detractors may well continue to label it as an approach rather than an authentic theory. Skeptics may question the theory for a lack of empirical distinction between needs and motivations and the obstacles of measuring the gratification of needs. They may argue that the theory posits a rigid teleology within a functionalist approach (Cazeneuve, 1974). Or, as Carey and Kreiling (1974) argued, the utilitarianistic audience-centered interpretations will not suffice to decode popular culture consumption because "an effective theory of popular culture will require a conception of man, not as psychological or sociological man, but as cultural man” (p. 242). Finally, Finn (1997) questioned the ability of U\&G researchers to solve the enigma of "linking personality traits to patterns of mass media use without accounting for alternative sources of gratification in the interpersonal domain" (p. 11). Yet, even critical scholars recognize that $U \& G$ research, chiefly pioneered by postwar social psychologists, has brought to the forefront the concept that the audience's perceptions of media messages may be altogether different from the meanings intended by their producers (Stevenson, 1997).

For its advocates, however, U\&G is still touted as one of the most influential theories in the field of communication research (Lin, 1998). Furthermore, the concept 
of needs, which most U\&G theorists embrace as a central psychological concept, is nearly irreproachable in more established disciplines. Within psychology, need is the bedrock of some of the discipline's most important theoretical work, including cognitive dissonance theory, social exchange theory, attribution theory, and some types of psychoanalytic theory (Lull, 1995). Samuels (1984) suggested physiological and psychological needs such as self-actualization, cognitive needs (such as curiosity), aesthetic needs, and expressive needs are inherent in every individual and central to human experience. Additionally, human needs are influenced by culture, not only in their formation but in how they are gratified. "Thus, culturally situated social experience reinforces basic biological and psychological needs while simultaneously giving direction to their sources of gratification" (Lull, 1995, p. 99). Lull further suggested that the study of how and why individuals use media, through $\mathrm{U} \& \mathrm{G}$ research, may offer clues to our understanding about exactly what needs are, where they originate, and how they are gratified.

Unfortunately, the polemic over whether U\&G satisfies the standard of a full-fledged theory continues. In part it may be due to the antiquated perception that any communication theory is inherently deficient to the traditional disciplines of sociology and psychology. Even more acrimonious is continued criticism by critical and cultural scholars that the perspective embodies a functionalist approach. Certainly, early U\&G emanated from a functionalist theoretical framework; a sociological theory that theorized patterned social phenomena leading to specific social consequences. However, Lin (1996) argued that this functionalist approach provides the "means-ends orientation [for the perspective and] opens up a world of opportunities for studying mediated communication as a functional process that is purposive and leads to specific psychological or social consequences" (p. 2). Additionally, Massey (1995) contended that qualitative communication scholars may find it difficult to advance the "illumination of audience interaction with the media" (p. 17) if they reject the questions, methods, and determinist results of U\&G research. Newhagen and Rafaeli (1996) suggested that mass media scholars will eventually have to address profound societal ramifications of new media. However, $U \& G$ theory offers researchers the ability to examine challenges and barriers to access that individual users are currently experiencing.

\section{U\&G: A CUTTING-EDGE THEORY}

By and large, U\&G has always provided a cutting-edge theoretical approach in the initial stages of each new mass communications medium: newspapers, radio, television, and now the Internet. It may be argued that the timely emergence of computer-mediated communication has only bolstered the theoretical potency of $U \& G$ by allowing it to stimulate productive research into a proliferating telecommunications medium. Lin (1996) argued that the primary strength of U\&G theory is its abil- 
ity to permit researchers to investigate "mediated communication situations via a single or multiple sets of psychological needs, psychological motives, communication channels, communication content, and psychological gratifications within a particular or cross-cultural context" (p. 574). For example, the use of personal computers has been linked to individuals' motivations to use the Internet for communication purposes linked to the fulfillment of gratifications such as social identity, interpersonal communication, parasocial interaction, companionship, escape, entertainment, and surveillance. As new communication technologies rapidly materialize, the range of possible topics for $U \& G$ research also multiplies. This flexibility is particularly important as we enter an information age in which computer-mediated communication permeates every aspect of our individual and social lives.

\section{U\&G AND ITS ROLE IN THE 21ST CENTURY}

The Internet lies at the locus of a new media ecology that has "altered the structural relations among traditional media such as print and broadcast and unites them around the defining technologies of computer and satellite" (Carey, 1998, p. 34). This convergence makes the old print-electronic and verbal-nonverbal distinctions, so long the focus of communication researchers, less relevant in light of messages that combine writing, still and animated images, and voices and other sounds (Weaver, 1993). For users, text, voice, pictures, animation, video, virtual reality motion codes, and even smell have already become part of the Internet experience (Newhagen \& Rafaeli, 1996). Communication on the Internet travels at unparalleled velocity. The Internet offers its audience an immense range of communication opportunities. Networks are always “up," allowing 24-hour asynchronous or synchronous interactions and information retrieval and exchange among individuals and groups (Kiesler, 1997). Fortuitous for U\&G researchers, communication on the Internet also leaves a trail that is easily traceable. Messages have time stamps, accurate to one hundredth of a second. Content is readily observable, recorded, and copied. Participant demography and behaviors of consumption, choice, attention, reaction, and learning afford extraordinary research opportunities (Newhagen \& Rafaeli, 1996). James et al. (1995) suggested Internet forums such as electronic bulletin boards fulfill many expectations of both mass and interpersonal communication. Hence, if the Internet is a new dominion of human activity, it is also a new dominion for $U \& G$ researchers.

If the Internet is a technology that many predict will be genuinely transformative, it will lead to profound changes in media users' personal and social habits and roles. The Internet's growth rates are exponential. The number of users has doubled in each of the last 6 years. If this development continues at the same rate, the Internet will soon be as widely disseminated a medium in daily usage as television or the telephone (Quarterman \& Carl-Mitchell, 1993). Thus, electronic communication technology may sufficiently alter the context of media use that cur- 
rent mass communication theories do not yet address. Some foresee, for example, that soon the novelty of combining music, video, graphics, and text will wane, and more natural methods will be created for Web users to interact in, such as data "landscapes" (Aldersey-Williams, 1996). Others predict a move beyond studying single users, two-person ties, and small groups, to analyzing the computer-supported social networks that flourish in areas as diverse as the workplace and in virtual communities (Garton, Haythornthwaite, \& Wellman, 1997). Gilder (1990) argued that the new media technologies like the Internet will empower individuals by "blowing apart all monopolies, hierarchies, pyramids, and power grids of established society" (p. 32). Others caution that the Internet is becoming more institutionally and commercially driven and is beginning to be "less the egalitarian cyberspace of recent memory than it does a tacky, crowded-with-billboards freeway exit just before any major tourist destination in the U.S." (Riley, Keough, Christiansen, Meilich, \& Pierson, 1998, p. 3).

Theoretically and practically, for U\&G scholars, however, the basic questions remain the same. Why do people become involved in one particular type of mediated communication or another, and what gratifications do they receive from it? Although we are likely to continue using traditional tools and typologies to answer these questions, we must also be prepared to expand our current theoretical models of $U \& G$ to include concepts such as interactivity, demassification, hypertextuality, asynchroneity, and interpersonal aspects of mediated communication. Then, if we are able to situate a "modernized" U\&G theory within this new media ecology, in an evolving psychological, sociological, and cultural context, we should be able to anticipate a highly serviceable theory for the 21 st century.

\section{REFERENCES}

Abrahamson, D. (1998). The visible hand: Money, markets, and media evolution. Journalism and Mass Communication Quarterly, 75, 14-18.

Aldersey-Williams, H. (1996). Interactivity with a human face. Technology Review, 99, 34-40.

Anderson, D. R., Collins, P. A., Schmitt, K. L., \& Jacobvitz, R. S. (1996). Stressful life events and television viewing. Communication Research, 23, 243-260.

Anderson, J. A. (1996). Communication theory: Epistemological foundations. New York: Guilford.

Anderson, K. J., \& Revelle, W. (1995). Personality processes. Annual Review of Psychology, 46, 295-328.

Ang, I. (1985). Watching Dallas: Soap opera and the melodramatic imagination. London: Routledge.

Ang, S., \& Cummings, L. L. (1994). Panel analysis of feedback-seeking patterns in face-to-face, computer-mediated, and computer-generated communication environments. Perceptual and Motor Skills, 79, 67-73.

Anonymous. (1989). Functional displacement of traditional TV viewing by VCR owners. Journal of Advertising Research, 29(2), 18-23.

Armstrong, C. B., \& Rubin, A. M. (1989). Talk radio as interpersonal communication. Journal of Communication, 39(2), 84-94.

Atkin, D. (1993). Adoption of cable amidst a multimedia environment. Telematics \& Informatics, 10, 51-58. 
Ball-Rokeach, S. (1985). The origins of individual media-system dependency: A sociological framework. Communication Research, 12, 485-510.

Bantz, C. R. (1982). Exploring uses and gratifications: A comparison of reported uses of television and reported uses of favorite program type. Communication Research, 9, 352-379.

Barwise, T. P., Ehrenberg, A. S. C., \& Goodhardt, G. J. (1982). Glued to the box. Journal of Communication, 32(4), 22-29.

Berelson, B. (1949). What "missing the newspaper" means. In P. F. Lazarsfeld \& F. N. Stanton (Eds.), Communication research 1948-1949 (pp. 111-129). New York: Harper.

Berelson, B., Lazarsfeld, P. F., \& McPhee, W. N. (1954). Voting: A study of opinion formation in a presidential campaign. Chicago: University of Chicago Press.

Bergeron, B. P., \& Bailin, M. T. (1997). The contribution of hypermedia link authoring. Technical Communication, 44, 121-128.

Blumler, J. G. (1979). The role of theory in uses and gratifications studies. Communication Research, 6 , 9-36.

Blumler, J. G. (1985). The social character of media gratifications. In K. E. Rosengren, L. A. Wenner, \& P. Palmgreen (Eds.), Media gratifications research: Current perspectives (pp. 41-59). Beverly Hills, CA: Sage.

Bryant, J., \& Zillman, D. (1984). Using television to alleviate boredom and stress. Journal of Broadcasting, 28, 1-20.

Cantril, H. (1940). The invasion from Mars: A study in the psychology of panic. Princeton, NJ: Princeton University Press.

Cantril, H. (1942). Professor quiz: A gratifications study. In P. F. Lazarsfeld \& F. Stanton (Eds.), Radio research 1941 (pp. 34-45). New York: Duell, Sloan \& Pearce.

Cantril, H., \& Allport, G. (1935). The psychology of radio. New York: Harper.

Carey, J. W. (1998). The Internet and the end of the National Communication System: Uncertain predictions of an uncertain future. Journalism and Mass Communication Quarterly, 75(1), 28-34.

Carey, J. W., \& Kreiling, A. L. (1974). Popular culture and uses and gratifications: Notes toward an accommodation. In J. G. Blumler \& E. Katz (Eds.), The uses of mass communications: Current perspectives on gratifications research (pp. 225-248). Beverly Hills, CA: Sage.

Cattell, R. B., Edger, H. W., \& Tatsuoka, M. M. (1970). Handbook for the Sixteen Personality Factor Questionnaire. Champaign, IL: Institute of Personality and Ability Testing.

Cazeneuve, E. (1974). Television as a functional alternative to traditional sources of need satisfaction. In J. G. Blumler \& E. Katz (Eds.), The uses of mass communications: Current perspectives on gratifications research (pp. 213-224). Beverly Hills, CA: Sage.

Chamberlain, M. A. (1994). New technologies in health communication. American Behavioral Scientist, 38, 271-284.

Cohen, A. A. (1981). People without media: Attitudes and behavior during a general media strike. Journal of Broadcasting, 25, 171-180.

Cooper, R. (1996). The status and future of audience duplication research: An assessment of ratings-based theories of audience behavior. Journal of Broadcasting \& Electronic Media, 40, 96-116.

Cooper, R. (1997). Japanese communication research: The emphasis on macro theories of media in an information based environment. Journal of Broadcasting \& Electronic Media, 41, 284-288.

Cowles, D. (1989). Consumer perceptions of interactive media. Journal of Broadcasting \& Electronic Media, 33, 83-89.

de Bock, H. (1980). Gratification frustration during a newspaper strike and a TV blackout. Journalism Quarterly, 57, 61-66, 78.

December, J. (1996). Units of analysis for Internet communication. Journal of Communication, 46(1), $14-37$.

DeFleur, M. L., \& Ball-Rokeach, S. (1982). Theories of mass communication (4th ed.). New York: Longman. 
Dervin, B. (1980). Communication gaps and inequities: Moving toward a reconceptualization. In B. Dervin \& M. J. Voight (Eds.), Progress in communication sciences (Vol. 2, pp. 73-112). Norwood, NJ: Ablex.

Dicken-Garcia, H. (1998). The Internet and continuing historical discourse. Journalism and Mass Communication Quarterly, 75, 19-27.

Dobos, J. (1992). Gratification models of satisfaction and choice of communication channels in organizations. Communication Research, 19, 29-51.

Donohew, L., Finn, S., \& Christ, W. G. (1988). The nature of news revisited: The roles of affect, schemas, and cognition. In L. Donohew, H. E. Sypher, \& E. T. Higgins (Eds.), Communication, social cognition and affect (pp. 195-218). Hillsdale, NJ: Lawrence Erlbaum Associates, Inc.

Donohew, L., Palmgreen P., \& Rayburn, J. D., II. (1987). Social and psychological origins of media use: A lifestyle analysis. Journal of Broadcasting \& Electronic Media, 31, 255-278.

Dorsher, M. (1996, August). Whither the public sphere: Prospects for cybersphere. Paper presented at the Media, Technology, and Community Conference, Grand Forks, ND.

Dozier, D. M., \& Rice, R. E. (1984). Rival theories of electronic newsgathering. In R. E. Rice (Ed.), The new media: Communication, research, and technology (pp. 103-128). Beverly Hills, CA: Sage.

Dunleavy, P., \& Weir, S. (1998). How to freshen up democracy. New Statesman, 11, 535, 571-572.

Dutton, W. H., Rogers, E. M., \& Jun, S. (1987). Diffusion and social impact of personal computers. Communication Research, 14, 219-249.

Dyson, E. (1993). Interactivity means "active" participation. Computerworld, 27(50), 33-34.

Eastman, S. T. (1979). Uses of television viewing and consumer life styles: A multivariate analysis. Journal of Broadcasting, 23, 491-500.

Eighmey, J. (1997). Profiling user responses to commercial Web sites. Journal of Advertising Research, 37(3), 59-66.

Eighmey, J., \& McCord, L. (1995, November). Adding value in the information age: Uses and gratifications of the World-Wide Web. Paper presented at the Conference on Telecommunications and Information Markets. Newport, RI.

Elliott, P. (1974). Uses and gratifications research: A critique and a sociological alternative. In J. G. Blumler \& E. Katz (Eds.), The uses of mass communications: Current perspectives on gratifications research (pp. 249-268). Beverly Hills, CA: Sage.

Eysenck, H. J. (1991). Dimensions of personality: 16, 5, or 3? —Criteria for a taxonomic paradigm. Personality and Individual Differences, 12, 773-790.

Ferguson, D. A. (1992). Channel repertoire in the presence of remote control devices, VCRs and cable television. Journal of Broadcasting \& Electronic Media, 36, 83-91.

Ferguson, D. A., \& Perse, E. M. (1994, March). Viewing television without a remote: A deprivation study. Paper presented at the annual meeting of the Research Division, Broadcast Education Association, Las Vegas, NV.

Finn, S. (1997). Origins of media exposure: Linking personality traits to TV, radio, print, and film use. Communication Research, 24, 507-529.

Fishbein, M., \& Ajzen, I. (1975). Belief, attitude, and behavior. Reading, MA: Addison-Wesley.

Fredin, E. S., \& David, P. (1998). Browsing and the hypermedia interaction cycle: A model of self-efficacy and goal dynamics. Journalism and Mass Communication Quarterly, 75, 35-54.

Fry, D. L., \& McCain, T. A. (1983). Community influentials' media dependency in dealing with a controversial local issue. Journalism Quarterly, 60, 458-463.

Fulk, J., Flanagin, A. J., Kalman, A. E., Monge, P. R., \& Ryan, T. (1996). Connective and communal public goods in interactive communication systems. Communication Theory, 6, 60-87.

Funk, J. B., \& Buchman, D. D. (1996). Playing violent video and computer games and adolescent self-concept. Journal of Communication, 46(2), 19-32.

Galloway, J. J., \& Meek, F. L. (1981). Audience uses and gratifications: An expectancy model. Communication Research, 8, 435-449. 
Gandy, O. H., Jr., Matabane, P. W., \& Omachonu, J. O. (1987). Media use, reliance, and active participation. Communication Research, 14, 644-663.

Garramone, G. (1984). Audience motivation effects: More evidence. Communication Research, 11, 79-96.

Garramone, G. (1985). Motivation and selective attention to political information formats. Journalism Quarterly, 62, 37-44.

Garramone, G. M., Harris, A. C., \& Anderson, R. (1986). Uses of political computer bulletin boards. Journal of Broadcasting \& Electronic Media, 30, 325-339.

Garrison, B. (1995). Online services as reporting tools: Daily newspaper use of commercial databases in 1994. Newspaper Research Journal, 16(4), 74-86.

Garton, L., Haythornthwaite, C., \& Wellman, B. (1997). Studying online social networks. Journal of Computer-Mediated Communication, 3(1). Retrieved May 1999 from the World Wide Web: http://jcmc.huji/ vol3/issue1/garton.html\#ABSTRACT

Geiger, S., \& Newhagen, J. (1993). Revealing the black box: Information processing and media effects. Journal of Communication, 43(4), 42-50.

Gerson, W. (1966). Mass media socialization behavior: Negro-Whites differences. Social Forces, 45, $40-50$.

Gilder, G. (1990). Life after television. Knoxville, TN: Whittle Direct.

Goodhardt, G. J., Ehrenberg, A. S. C., \& Collins, M. A. (1987). The television audience: Patterns of viewing (2nd ed.). Aldershot, England: Gower.

Grant, A. E., Guthrie, K. K., \& Ball-Rokeach, S. (1991). Television shopping: A media dependency perspective. Communication Research, 18, 773-798.

Greenberg, B. S. (1974). Gratifications of television viewing and their correlates for British children. In J. G. Blumler \& E. Katz (Eds.), The uses of mass communications: Current perspectives on gratifications research (pp. 71-92). Beverly Hills, CA: Sage.

Greenberg, B. S., \& Dominick, J. (1969). Race and social class differences in teenager's use of television. Journal of Broadcasting, 13(4), 331-344.

Grunig, J. E. (1979). Time budgets, level of involvement and use of the mass media. Journalism Quarterly, 56, 248-261.

Ha, L. (1995). Subscriber's behavior in electronic discussion groups: A comparison between academics and practitioners. In Proceedings of the first annual conference on telecommunications and information markets (pp. 27-36).

Ha, L., \& James, E. L. (1998). Interactivity reexamined: A baseline analysis of early business Web sites. Journal of Broadcasting \& Electronic Media, 42, 457-474.

Hawkins, R. P., \& Pingree, S. (1981). Uniform messages and habitual viewing: Unnecessary assumptions in social reality effects. Human Communication Research, 7, 291-301.

Heeter, C. (1989). Implications of new interactive technologies for conceptualizing communication. In J. L. Salvaggio \& J. Bryant (Eds.), Media use in the information age: Emerging patterns of adoption and consumer use (pp. 217-235). Hillsdale, NJ: Lawrence Erlbaum Associates, Inc.

Heeter, C., \& Greenberg, B. (1985). Cable and program choice. In D. Zillman \& J. Bryant (Eds.), Selective exposure to communication (pp. 203-224). Hillsdale, NJ: Lawrence Erlbaum Associates, Inc.

Herzog, H. (1940). Professor quiz: A gratification study. In P. F. Lazarsfeld \& F. N. Stanton (Eds.), Radio and the printed page (pp. 64-93). New York: Duell, Sloan \& Pearce.

Herzog, H. (1944). What do we really know about daytime serial listeners? In P. F. Lazarsfeld \& F. N. Stanton (Eds.), Radio research 1942-1943 (pp. 3-33). New York: Duell, Sloan \& Pearce.

Horna, J. (1988). The mass media as leisure: A western-Canadian case. Society and Leisure, 11, 283-301.

Jackson, M. H. (1997). Assessing the structure of communication on the World Wide Web. Journal of Computer-Mediated Communication, 3. Retrieved May 1999 from the World Wide Web: http://jcmc.huji.ac. il/vol3/issue1/jackson.html\#ABSTRACT 
Jacobs, R. (1995). Exploring the determinants of cable television subscriber satisfaction. Journal of Broadcasting \& Electronic Media, 39, 262-274.

James, M. L., Wotring, C. E., \& Forrest, E. J. (1995). An exploratory study of the perceived benefits of electronic bulletin board use and their impact on other communication activities. Journal of Broadcasting \& Electronic Media, 39, 30-50.

Jensen, K. B., \& Jankowski, N. W. (1991). A handbook of qualitative methodologies for mass communication research. New York: Routledge.

Katz, E. (1960). The two-step flow of communication. In W. Schramm (Ed.), Mass communications (pp. 346-365). Urbana: University of Illinois Press.

Katz, E. (1987). Communication research since Lazarsfeld. Public Opinion Quarterly, 51, 525-545.

Katz, E., Blumler, J., \& Gurevitch, M. (1974). Utilization of mass communication by the individual. In J. Blumler \& E. Katz (Eds.), The uses of mass communication: Current perspectives on gratifications research (pp. 19-34). Beverly Hills, CA: Sage.

Katz, E., \& Foulkes, D. (1962). On the use of mass media as escape: Clarification of a concept. Public Opinion Quarterly, 26, 377-388.

Katz, E., Gurevitch, M., \& Haas, H. (1973). On the use of the mass media for important things. American Sociological Review, 38, 164-181.

Katz, E., \& Lazarsfeld, P. F. (1955). Personal influence: The part played by people in the flow of mass communications. Glencoe, IL: Free Press.

Kiesler, S. (Ed.). (1997). Culture of the Internet. Mahwah, NJ: Lawrence Erlbaum Associates, Inc.

Kimball, P. (1959). People without papers. Public Opinion Quarterly, 23, 389-398.

Klapper, J. T. (1960). The effects of mass communication. New York: Free Press.

Klapper, J. T. (1963). Mass communication research: An old road resurveyed. Public Opinion Quarterly, 27, 515-527.

Kubey, R. (1986). Television use in everyday life: Coping with unstructured time. Journal of Communication, 36(3), 108-123.

Kubey, R., \& Csikszentmihalyi, M. (1990). Television and the quality of life. Hillsdale, NJ: Lawrence Erlbaum Associates, Inc.

Kuehn, S. A. (1994). Computer-mediated communication in instructional settings: A research agenda. Communication Education, 43, 171-182.

LaRose, R., \& Atkin, D. (1991). An analysis of pay-per-view versus other movie delivery modalities. Journal of Media Economics, 4, 3-17.

Lazarsfeld, P. F., Berelson, B., \& Gaudet, H. (1948). The people's choice (2nd ed.). New York: Columbia University Press.

Lazarsfeld, P. F., \& Stanton, F. (1942). Radio research, 1942-1943. New York: Duell, Sloan \& Pearce.

Lazarsfeld, P. F., \& Stanton, F. (1944). Radio research, 1941. New York: Duell, Sloan \& Pearce.

Lazarsfeld, P. F., \& Stanton, F. (1949). Communication research 1948-1949. New York: Harper \& Row.

Leeds-Hurwitz, W. (1992). Social approaches to interpersonal communication. Communication Theory, 2, 131-139.

Lemish, D. (1985). Soap opera viewing in college: A naturalistic inquiry. Journal of Broadcasting \& Electronic Media, 29, 275-293.

Levy, M. R., \& Windahl, S. (1984). Audience activity and gratifications: A conceptual clarification and exploration. Communication Research, 11, 51-78.

Lichtenstein, A., \& Rosenfeld, L. B. (1983). Uses and misuses of gratifications research: An explication of media functions. Communication Research, 10, 97-109.

Liebes, T., \& Katz, E. (1990). The export of meaning. New York: Oxford University Press.

Lin, C. A. (1993). Exploring the role of the VCR use in the emerging home entertainment culture. Journalism Quarterly, 70, 833-842.

Lin, C. A. (1996). Looking back: The contribution of Blumler and Katz's uses and mass communication to communication research. Journal of Broadcasting \& Electronic Media, 40, 574-581. 
Lin, C. A. (1998). Exploring personal computer adoption dynamics. Journal of Broadcasting \& Electronic Media, 42, 95-112.

Lind, R. A. (1995). How can TV news be improved?: Viewer perceptions of quality and responsibility. Journal of Broadcasting \& Electronic Media, 39, 360-375.

Loges, W. E., \& Ball-Rokeach, S. (1993). Dependency relations and newspaper readership. Journalism Quarterly, 70, 601-614.

Lometti, G. E., Reeves, B., \& Bybee, C. R. (1977). Investigating the assumptions of uses and gratifications research. Communication Research, 4, 321-328.

Lowery, S., \& DeFleur, M. L. (1983). Milestones in mass communication research. New York: Longman.

Lull, J. (1991). China turned on: Television, reform and resistance. London: Routledge.

Lull, J. (1995). Media, communication, culture: A global approach. New York: Columbia University Press.

Markus, M. L. (1994). Finding a happy medium: Explaining the negative effects of electronic communication on social life at work. ACM Transactions on Information Systems, 14, 119-149.

Massey, K. B. (1995). Analyzing the uses and gratifications concept of audience activity with a qualitative approach: Media encounters during the 1989 Loma Prieta earthquake disaster. Journal of Broadcasting \& Electronic Media, 39, 328-342.

McGuire, W. J. (1974). Psychological motives and communication gratifications. In J. G. Blumler \& E. Katz (Eds.), The uses of mass communications: Current perspectives on gratifications research ( $\mathrm{pp}$. 167-196). Beverly Hills, CA: Sage.

Mcllwraith, R. D. (1998). "I'm addicted to television": The personality, imagination, and TV watching patterns of self-identified TV addicts. Journal of Broadcasting \& Electronic Media, 42, 371-386.

McLeod, J. M., \& Becker, L. (1981). The uses and gratifications approach. In D. Nimmo \& K. Sanders (Eds.), Handbook of political communication (pp. 67-100). Beverly Hills, CA: Sage.

McLeod, J. M., Bybee, C. R., \& Durall, J. A. (1982). On evaluating news media performance. Political Communication, 10, 16-22.

McQuail, D. (1994). The rise of media of mass communication. In D. McQuail (Ed.), Mass communication theory: An introduction (pp. 1-29). London: Sage.

McQuail, D., Blumler, J., \& Brown, J. (1972). The television audience: A revised perspective. In D. McQuail (Ed.), Sociology of mass communications (pp. 135-165). Middlesex, England: Penguin.

Mendelsohn, H. (1964). Listening to the radio. In L. A. Dexter \& D. M. White (Eds.), People, society and mass communication (pp. 239-248). New York: Free Press.

Merton, R. K. (1949). Patterns of influence: A study of interpersonal influence and communications behavior in a local community. In P. F. Lazarsfeld \& F. N. Stanton (Eds.), Communication research, 1948-1949 (pp. 180-219). New York: Harper.

Morley, D. (1980). The nationwide audience. London: Film Institute.

Morley, D. (1986). Family television: Cultural power and domestic leisure. London: Routledge.

Morley, D. (1992). Television, audiences, and cultural studies. London: Routledge.

Morris, M., \& Ogan, C. (1996). The Internet as mass medium. Journal of Communications, 46(1), $39-50$.

Nelson, T. H. (1990). The right way to think about software design. In B. Laurel (Ed.), The art of human-computer interface design. Reading, MA: Addison-Wesley.

Newhagen, J., \& Rafaeli, S. (1996). Why communication researchers should study the Internet: A dialogue. Journal of Communications, 46(1), 4-13.

Nisbett, R., \& Wilson, T. (1977). Telling more than we can know: Verbal reports on mental processes. Psychological Review, 84, 231-259.

Ostman, R. E., \& Jeffers, D. W. (1980, June). The relationship of life-stage to motives for using television and the perceived reality of TV. Paper presented at the International Communication Association convention, Acapulco, Mexico. 
Palmgreen, P. (1984). Uses and gratifications: A theoretical perspective. In R. Bostrom (Ed.), Communication Yearbook 8 (pp. 20-55). Beverly Hills, CA: Sage.

Palmgreen, P., \& Rayburn, J. D., II. (1979). Uses and gratifications and exposure to public television. Communication Research, 6, 155-180.

Palmgreen, P., \& Rayburn, J. D., II. (1982). Gratifications sought and media exposure: An expectancy value model. Communication Research, 9, 561-580.

Palmgreen, P., \& Rayburn, J. D., II. (1985). A comparison of gratification models of media satisfaction. Communication Monographs, 52, 334-346.

Perse, E. M., \& Courtright, J. A. (1993). Normative images of communication research. Human Communication, 19, 485-503.

Perse, E. M., \& Dunn, D. G. (1998). The utility of home computers and media use: Implications of multimedia and connectivity. Journal of Broadcasting \& Electronic Media, 42, 435-456.

Perse, E. M., \& Rubin, A. M. (1988). Audience activity and satisfaction with favorite television soap opera. Journalism Quarterly, 65, 368-375.

Pool, I. D. (1983). Technologies of freedom. Cambridge, MA: Harvard University Press.

Quarterman, J. S., \& Carl-Mitchell, S. (1993). The computing paradigm shift. Journal of Organizational Computing, 3, 31-50.

Radway, J. (1984). Reading the romance: Feminism, and the representation of women in popular culture. Chapel Hill: University of North Carolina Press.

Rafaeli, S. (1986). The electronic bulletin board: A computer-driven mass medium. Computers and the Social Sciences, 2, 123-136.

Rayburn, J. D. (1996). Uses and gratifications. In M. B. Salwen \& D. W. Stacks (Eds.), An integrated approach to communication theory and research (pp. 97-119). Mahwah, NJ: Lawrence Erlbaum Associates, Inc.

Rayburn, J. D., \& Palmgreen, P. (1984). Merging uses and gratifications and expectancy-value theory. Communication Research, 11, 537-562.

Reagan, J. (1996). The "repertoire" of information sources. Journal of Broadcasting \& Electronic Media, 40, 112-119.

Rice, R. E., \& Williams, F. (1984). Theories old and new: The study of the new media. In R. E. Rice (Ed.), The new media: Communication, research, and technology (pp. 55-80). Beverly Hills, CA: Sage.

Riley, P., Keough, C. M., Christiansen, T., Meilich, O., \& Pierson, J. (1998). Community or colony: The case of online newspapers and the Web. Journal of Computer-Mediated Communication, 4. Retrieved May 1999 from the World Wide Web: http://jcmc.huji.ac.il/vol4/ issue1/keough.html\#ABSTRACT

Roe, K. (1983). Mass media and adolescent schooling: Conflict or co-existence? Stockholm, Sweden: Almqvist \& Wiksell.

Rogers, E. (1986). Communication technology: The new media. New York: Free Press.

Rosengren, K. E. (1974). Uses and gratifications: A paradigm outlined. In J. G. Blumler \& E. Katz (Eds.), The uses of mass communications: Current perspectives on gratifications research (pp. 269-286). Beverly Hills, CA: Sage.

Rosengren, K. E., Johnsson-Smaragdi, U., \& Sonesson, I. (1994). For better and for worse: effects studies and beyond. In K. E. Rosengren (Ed.), Media effects and beyond: Culture, socialization and lifestyles (pp. 302-315). New York: Routledge.

Rosengren, K. E., \& Windahl, S. (1989). Media matter: TV use in childhood and adolescence. Norwood: NJ: Ablex.

Rosenstein, A. W., \& Grant, A. E. (1997). Reconceptualizing the role of habit: A new model of television audience. Journal of Broadcasting \& Electronic Media, 41, 324-344.

Rubin, A. M. (1981). An examination of television viewing motivations. Communication Research, 8, $141-165$. 
Rubin, A. M. (1983). Television uses and gratifications: The interactions of viewing patterns and motivations. Journal of Broadcasting, 27, 37-51.

Rubin, A. M. (1984). Ritualized and instrumental television viewing. Journal of Communication, 34(3), $67-77$.

Rubin, A. M. (1986). Uses, gratifications, and media effects research. In J. Bryant \& D. Zillmann (Eds.), Perspectives on media effects (pp. 281-301). Hillsdale, NJ: Lawrence Erlbaum Associates, Inc.

Rubin, A. M. (1994a). Audience activity and media use. Communication Monographs, 60, 98-105.

Rubin, A. M. (1994b). Media uses and effects: A uses and gratifications perspective. In J. Bryant \& D. Zillmann (Eds.), Media effects: Advances in theory and research (pp. 417-436). Hillsdale, NJ: Lawrence Erlbaum Associates, Inc.

Rubin, A. M., \& Windahl, S. (1986). The uses and dependency model of mass communication. Critical Studies in Mass Communication, 3, 184-199.

Samuels, F. (1984). Human needs and behavior. Cambridge, MA: Schnenkman.

Sandbothe, M. (1996). Interactivity—hypertexuality—transversality: A media-philosophical analysis of the Internet. Retrieved May 1999 from the World Wide Web: http://www.uni-jena.de/ms/tele/ part2.html

Schaefer, R. J., \& Avery, R. K. (1993). Audience conceptualizations of "Late night with David Letterman." Journal of Broadcasting \& Electronic Media, 37, 253-273.

Schramm, W. (1949). The nature of news. Journalism Quarterly, 26, 259-269.

Schramm, W., Lyle, J., \& Parker, E. (1961). Television in the lives of our children. Stanford, CA: Stanford University Press.

Severin, W. J., \& Tankard, J. W. (1997). Communication theories: Origins, methods, and uses in the mass media (4th ed.). New York: Longman.

Singer, J. B. (1998). Online journalists: Foundations for research into their changing roles. Journal of Computer-Mediated Communication, 4. Retrieved May 1999 from the World Wide Web: http:// jcmc.huji.ac.il/vol4/issue 1/smith.html\#ABSTRACT

Smith, C. B. (1997). Casting the net: Surveying an Internet population. Journal of Computer-Mediated Communication, 3. Retrieved May 1999 from the World Wide Web: http://jcmc.huji.ac.il/vol3/ issue $1 /$ singer.html\#ABSTRACT

Stanford, S. W. (1983). Comments on Palmgreen and Rayburn: Gratifications sought and media exposure. Communication Research, 10, 247-258.

Stevenson, N. (1997). Critical perspectives within audience research. In T. O'Sullivan \& Y. Jewkes (Eds.), The media studies reader. New York: St. Martin's.

Stolz, C. (1995). Silicon snake oil: Second thoughts on the information highway. New York: Doubleday.

Stone, G., \& Stone, D. (1990). Lurking in the literature: Another look at media use habits. Mass Communications Review, 17, 25-33.

Sundar, S. S. (1998). Effect of source attribution on perception of online news stories. Journalism and Mass Communication Quarterly, 75, 55-68.

Swanson, D. L. (1977). The uses and misuses of uses and gratifications. Human Communication Research, 3, 214-221.

Swanson, D. L. (1987). Gratification seeking, media exposure, and audience interpretations. Journal of Broadcasting \& Electronic Media, 31, 237-254.

Trevino, L. K., \& Webster, J. (1992). Flow in computer-mediated communication: Electronic mail and voice mail evaluation and impacts. Communication Research, 19, 539-573.

Thomas, P. J. (1995). Introduction: The social and interactional dimensions of human-computer interfaces. In P. J. Thomas (Ed.), The social and interactional dimensions of human-computer interfaces (pp. 1-10). Cambridge, England: Cambridge University Press.

Walker, J. R. (1990). Time out: Viewing gratifications and reactions to the 1987 NFL players' strike. Journal of Broadcasting \& Electronic Media, 34, 335-350. 
Walker, J. R., \& Bellamy, R. V. (1991). Gratifications of grazing: An exploratory study of remote control use. Journalism Quarterly, 68, 422-431.

Waples, D., Berelson, B., \& Bradshaw, F. R. (1940). What reading does to people. Chicago: University of Chicago Press.

Weaver, D. H. (1993). Communication research in the 1990s. In P. Gaunt (Ed.), Beyond agendas: New directions in communication research (pp. 199-220). Westport, CT: Greenwood.

Webster, J., \& Wakshlag, J. (1983). A theory of television program choice. Communication Research, 10, 430-446.

Weiss, W. (1976). Review of the uses of mass communications. Public Opinion Quarterly, 40, 132-133.

Wenner, L. A. (1985). The nature of news gratification. In K. E. Rosengren, L. A. Wenner, \& P. Palmgreen (Eds.), Media gratifications research: Current perspectives (pp. 171-194). Beverly Hills, CA: Sage.

White, R. A. (1994). Audience interpretation of media: Emerging perspectives. Communication Research Trends, 14(3), 3-36.

Williams, F., Phillips, A. F., \& Lum, P. (1985). Gratifications associated with new communication technologies. In K. E. Rosengren, L. A. Wenner, \& P. Palmgreen (Eds.), Media gratification research: Current perspectives (pp. 241-252). Beverly Hills, CA: Sage.

Williams, F., Rice, R. E., \& Rogers, E. M. (1988). Research methods and the new media. New York: Free Press.

Wimmer, R. D., \& Dominick, J. R. (1994). Mass media research: An introduction. Belmont, CA: Wadsworth.

Windahl, S. (1981). Uses and gratifications at the crossroads. Mass Communication Review Yearbook, 2, 174-185.

Windahl, S., Hojerback, I., \& Hedinsson, E. (1986). Adolescents without television: A study in media deprivation. Journal of Broadcasting \& Electronic Media, 30, 47-63.

Young, K. (1996, August). Internet addiction: The emergence of a new addictive disorder. Poster presented at the annual meeting of the American Psychological Association, Toronto, Canada.

Zillman, D., \& Bryant, J. (1985). Selective exposure to communication. Hillsdale, NJ: Lawrence Erlbaum Associates, Inc.

Zillman, D., \& Bryant, J. (1994). Entertainment as media effect. In J. Bryant \& D. Zillman (Eds.), Media effects: Advances in theory and research (pp. 437-461). Hillsdale, NJ: Lawrence Erlbaum Associates, Inc. 
Copyright of Mass Communication \& Society is the property of Lawrence Erlbaum Associates and its content may not be copied or emailed to multiple sites or posted to a listserv without the copyright holder's express written permission. However, users may print, download, or email articles for individual use. 